Article

\title{
Extracting Terrain Texture Features for Landform Classification Using Wavelet Decomposition
}

\author{
Yuexue $\mathrm{Xu}{ }^{1}$, Shengjia Zhang ${ }^{1}$, Jinyu Li ${ }^{1}$, Haiying Liu ${ }^{2, *}$ and Hongchun Zhu ${ }^{1}$ \\ 1 College of Geodesy and Geomatics, Shandong University of Science and Technology, Qingdao 266590, China; \\ skyuexue@sdust.edu.cn (Y.X.); 202083020107@sdust.edu.cn (S.Z.); 202083020029@sdust.edu.cn (J.L.); \\ hongchun@sdust.edu.cn (H.Z.) \\ 2 College of Computer Science and Engineering, Shandong University of Science and Technology, \\ Qingdao 266590, China \\ * Correspondence: skd991598@sdust.edu.cn
}

check for updates

Citation: Xu, Y.; Zhang, S.; Li, J.; Liu, H.; Zhu, H. Extracting Terrain Texture Features for Landform Classification Using Wavelet Decomposition. ISPRS Int. J. Geo-Inf. 2021, 10, 658. https:// doi.org/10.3390/ijgi10100658

Academic Editors: Josef Strobl, Liyang Xiong and Wolfgang Kainz

Received: 25 July 2021

Accepted: 27 September 2021

Published: 30 September 2021

Publisher's Note: MDPI stays neutral with regard to jurisdictional claims in published maps and institutional affiliations.

Copyright: (c) 2021 by the authors. Licensee MDPI, Basel, Switzerland. This article is an open access article distributed under the terms and conditions of the Creative Commons Attribution (CC BY) license (https:// creativecommons.org/licenses/by/ $4.0 /)$.

\begin{abstract}
Accurate landform classification is a crucial component of geomorphology. Although extensive classification efforts have been exerted based on the terrain factor, the scale analysis to describe the macro and micro landform features still needs standard measurement. To obtain the appropriate analysis scale of landform structure feature, and then carry out landform classification using the terrain texture, the texture feature is introduced for reflecting landform spatial differentiation and homogeneity. First, applying the ALOS World 3D-30m (AW3D30) DEM and selecting typical landforms of the southwest Tibet Plateau, the discrete wavelet transform (DWT), which acts as the texture feature analysis method, is executed to dissect the multiscale structural features of the terrain texture. Second, through the structural indices of reconstructed texture images, the optimum decomposition scale of DWT is confirmed. Under these circumstances, wavelet coefficients and wavelet energy entropy are extracted as texture features. Finally, the random forest (RF) method is utilized to classify the landform. Results indicate that the texture feature of DWT can achieve higher classification accuracy, which increases by approximately $11.8 \%$ compared with the gray co-occurrence matrix (GLCM).
\end{abstract}

Keywords: DEM; texture structure; wavelet decomposition scale; texture feature vector; landform classification

\section{Introduction}

Landforms, which are genetically related to one another, are a combination of various surface configurations, providing a solid foundation for geomorphology [1]. The classification principle should not only classify the landform types and embody the diversity of spatial structure, but also explain the formation mechanisms of landforms, which suffer from external forces in temporal and spatial sequence [2]. The geo-informatics graphic methodology has become a major analysis method, including the slope spectrum analysis, profile spectrum analysis, and terrain texture analysis [3-5]. Plentiful studies on landform classification, which is in accordance with slope spectrum features [6,7] and profile curvature $[8,9]$, have been conducted. However, the landform structure is inconvenient to grasp at different scales and lacks scale universality among different study areas. Terrain texture, as one of the elements of landform surface, has formed unique landform features $[10,11]$ and evolution laws under the action of an external agent [12]. According to the homogeneity and heterogeneity of different terrain texture features, the classification of landform types can be realized [13]. Given that image texture is a critical basis for describing macro features and detailed structures of landforms [4], the multiscale overall pattern, spatial distribution, and basic terrain direction of the regional landform were constructed in macro. Focusing on the skeleton of macro landform distribution pattern, the texture represents an important landform contour, weakening the single feature description of texture primitives 
at micro scale. Texture analysis methods supply objective conditions for carrying out the landform recognition and classification, as well as expand the content of digital terrain analysis technology [14-16]. Figure 1 shows the textures of the targeted landforms in different data.
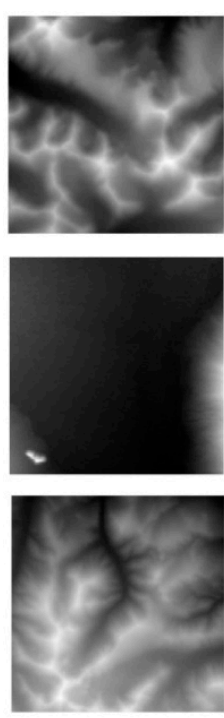

(a)
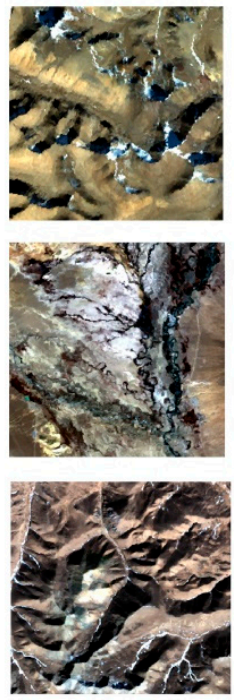

(b)
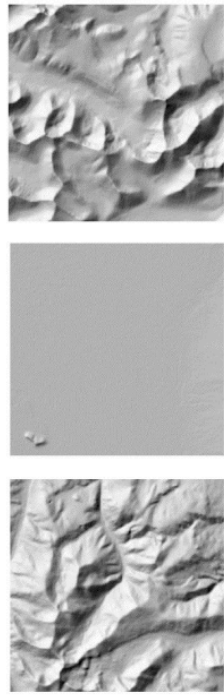

(c)

Figure 1. Textures of the targeted landforms in different data. (a) DEM texture; (b) Landsat- 8 texture; (c) Hillshade.

Textures are representative features for visual-based landform classification $[17,18]$, which have regional characteristics that are consistent with the terrain features. The correlation between texture and terrain analyses is reflected in the fact that texture is the gray scale mapping of the elevation value and is the arrangement and distribution pattern of landform relief in space with macroscopic regularity and local irregularity. At a certain scale, the terrain texture is the visual structure feature of landform unit in the image (texture primitive corresponds to the landform unit, showing the self-similarity of similar landform structures and periods, as well as the regional heterogeneity of different landforms). To date, four texture analysis methods can be applied for landform classification, which are statistical, model, structure, and signal methods [19]. Even the structure difference of texture feature is conducive to the landform classification and recognition [20], ensuring that an appropriate texture analysis model is essential to extract different texture features and types [21].

On account of the statistical texture analysis method, the gray co-occurrence matrix (GLCM) is proposed to extract terrain factors and texture feature values [22]. Subsequently, the terraced landforms are sorted using the classification and regression tree [23]. Similarly, Lan and Liu implemented the classification of woodland [21]. Combining the terrain factor and GLCM texture measure, the automatic recognition of loess landforms using the random forest (RF) method is achieved [24]. A discrete Laplacian convolution method, which depicts texture morphology, is applied to classify linear dune landforms in digital surface model images [25]. A multiscale LBP operator has also been used to describe the texture. Then, the texture measurement and region growth segmentation are combined to realize the recognition of coastal terrain targets [26]. Markov Random field (MRF) parameters are adopted to reduce the uncertainty of landform classification on Mars [27]. All these studies on texture feature extraction concentrate on the spatial domain, lacking the analysis of the relief change and spatial structure conveyed by the geomorphic origin. Considering that the significant landform features, which are in possession of good performance at spatial and frequency domains, multiscale texture features based on Fourier transform are extracted, and tropical areas are identified by superimposing landform relief features [28]. 
For the multiscale digital elevation model (DEM) texture image, the abilities to represent terrain parameters and identify landform types are discussed in different roughness algorithms [29].

Considering the above texture analysis methods, the statistical method computes the probability of adjacent pixels to delineate the second-order texture statistical features [30], whereas the spatial structure features of landforms are thoughtless. Points, lines, and polygons, including textures generated by the three, correspond to the structure feature of texture information. The premise of applying the structural method is how to determine the texture primitive [31], whereas that of extracting the random terrain texture is a difficult matter due to landform relief. The key to the model method is how the texture model, constructed closest to the original landform of the image, is revealed [32]. The spectrum method can display the shape [33] and period of a landform structure in the same way as the atlas and obtain the statistical features of texture, which is a preferable comprehensive texture analysis method. One of the challenges in texture analysis is the shortage of adequate tools to express effective textures at different scales. Wavelet transforms contribute to overcoming this issue. Therefore, the method is utilized in this study for texture analysis, attempting to quantitatively investigate the spectrum features of different textures, and to qualitatively extract landform features in the frequency and spatial domains. From the perspective of geography, the scene classification of different landforms should be based on the landform unit, requiring the data source to be a combination of landform relief and geometric morphology textures. DEM images satisfy these conditions [34,35].

The low frequency information of DEM texture is abundant in a region with small relief, whereas the high frequency information of DEM texture changes rapidly in the region with large relief [36]. The high-pass frequency of wavelet transform determines the anomaly of local features related to the landform structure. For example, when the profile of terrain relief converts into the frequency domain, the singularity of landforms or the specific frequency change of different topographic waves can be located in space [37]. The scale analysis is an essential part of landform feature extraction. Given that diverse and complex landform structures emerge in high-resolution DEM images, the structural heterogeneity of textures at different scales should be discussed. The wavelet transform can reach the effect of spatial structure difference between macro and micro landforms through multilevel decomposition. Similarly, the detailed wavelet coefficients facilitate the quantitative analysis of the horizontal and vertical reliefs of the landforms. Moreover, the approximate wavelet coefficient can be a competent for representing landform smoothness. Therefore, in terms of low- and high-dimensional feature vectors calculated by the wavelet transform, a neural network can be used to train the texture for landform classification [38].

The terrain texture features of China's typical landform sample areas are widely expressed in DEM images [39]. To fully explore the level of landform information, the texture analysis method of wavelet transform, which analyzes the landform structure of a DEM texture image, is also a valuable research topic. Therefore, the DEM texture image is taken as the data source, and the samples of landform are selected in the southwestern Tibet Plateau. The specific objectives are as follows: (1) As for texture feature extraction, the wavelet transform is used to analyze the structure features of landforms by means of appropriate decomposition scales; (2) Two texture features (wavelet coefficients and wavelet energy entropy) and GLCM texture measures are extracted quantitatively to discuss the difference analysis; (3) Ultimately, the RF classification method is adopted to train the texture feature vectors, and the classification accuracy result of the wavelet transform is assessed.

\section{Materials and Methods}

\subsection{Study Area and Data}

Landforms in the southwest Tibet Plateau are complex and diverse [40,41], where the overall topography is the transition from northwest to southeast, and automatic landform classification is urgently needed. After the long-term river erosion and geological processes, 
the mountainous landforms with ups and downs are created [42]. According to the classification scheme of digital land geomorphology of 1:1,000,000 in China, seven typical sample types [43], which cater to the altitude and morphological indices, are selected [44]: (1) A0: High relief extremely high altitude mountain; (2) A1: High altitude plain; (3) A2: Intermediate relief high mountain; (4) A3: Intermediate relief middle mountain; (5) A4: Low relief extremely high mountain; (6) A5: Extremely high altitude plain; and (7) A6: Extremely high altitude high-hill. The location distribution is illustrated in Figure 2. The experimental data ALOS World 3D-30 m (AW3D30) DEM products, provided by JAXA and ASTER GDEM [45,46], both have a $30 \mathrm{~m}$ resolution. Regarding the validation of height accuracy, the RMSE value of AW3D30 DEM is $4.40 \mathrm{~m}$ [47], whereas the linear error at 95\% probability (LE95) and the RMSE of ASTER GDEM are 17 and $8.7 \mathrm{~m}$, respectively [48]. DEM carries plentiful texture information, not only the texture spatial cognition of different landforms can be obtained from visual perception, but also the texture heterogeneity of regional landforms can be quantitatively studied. Moreover, the texture information of classification feature space can be derived. The DEM texture offers reliable depictions and discriminations of various landforms, especially macroscale terrain information at a certain scale, which promotes the improvement of geomorphological mapping via the terrain texture.

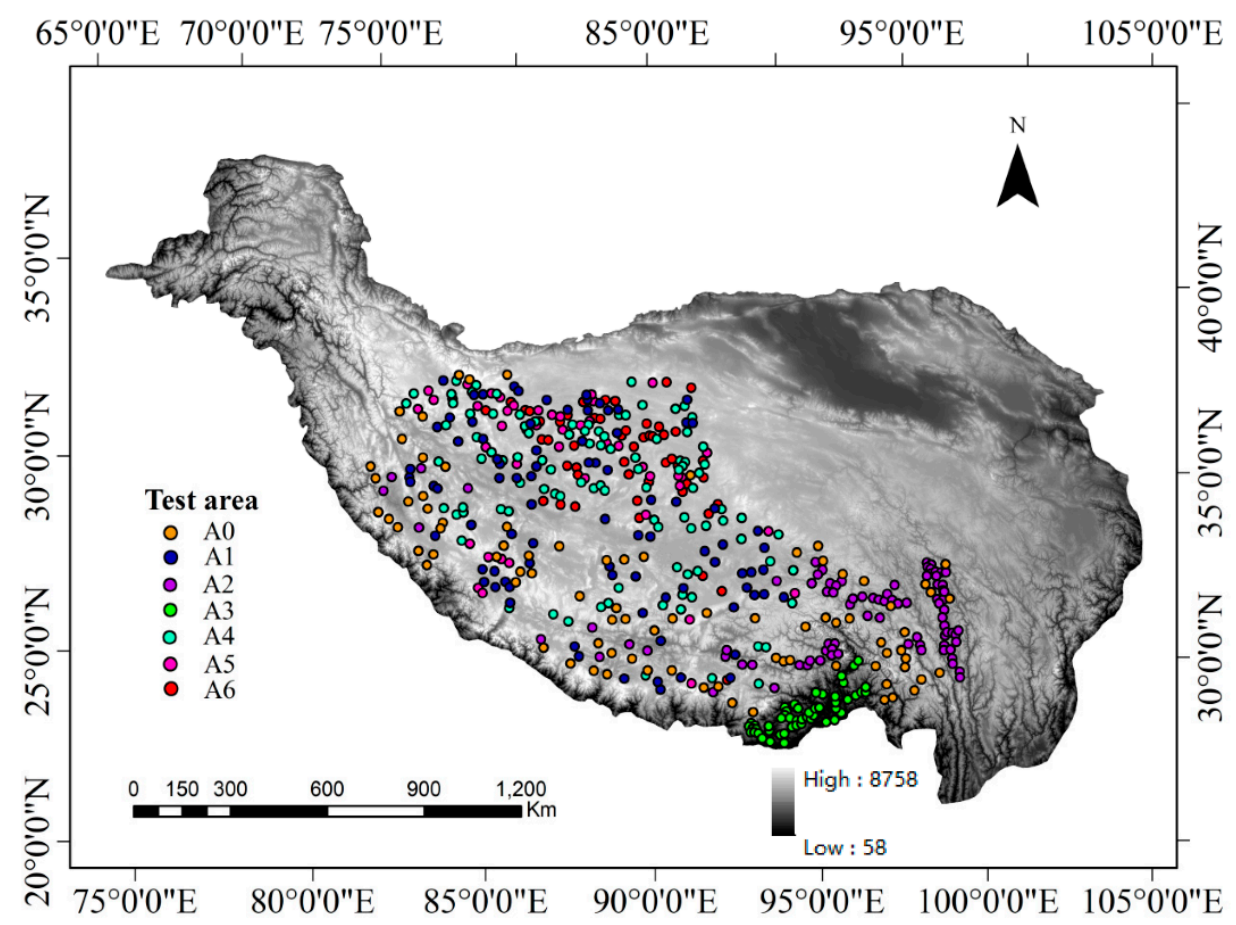

Figure 2. Location distribution of samples in the southwestern Tibetan Plateau. A0: High relief extremely high altitude mountain; A1: High altitude plain; A2: Intermediate relief high mountain; A3: Intermediate relief middle mountain; A4: Low relief extremely high mountain; A5: Extremely high altitude plain; A6: Extremely high altitude high-hill.

\subsection{Methods}

Geomorphic ontology is the core and basic methodology of landform classification that determines the macroscopic direction of geomorphic research. As the visual perception object, terrain textures should be analyzed completely whether in the characteristic change of spatial pattern or the landform fluctuation of frequency domain. Therefore, the extraction and analysis of multiscale landform structure features are performed according to the wavelet transform. In addition, the parameters of the decomposition scales and vectors of wavelet texture features are obtained at a later time. The former theory offers a precondition for the latter classification process using the RF method. In terms of the different texture 
feature extraction methods, the classification accuracy of landforms is compared. The specific technical route is displayed in Figure 3.

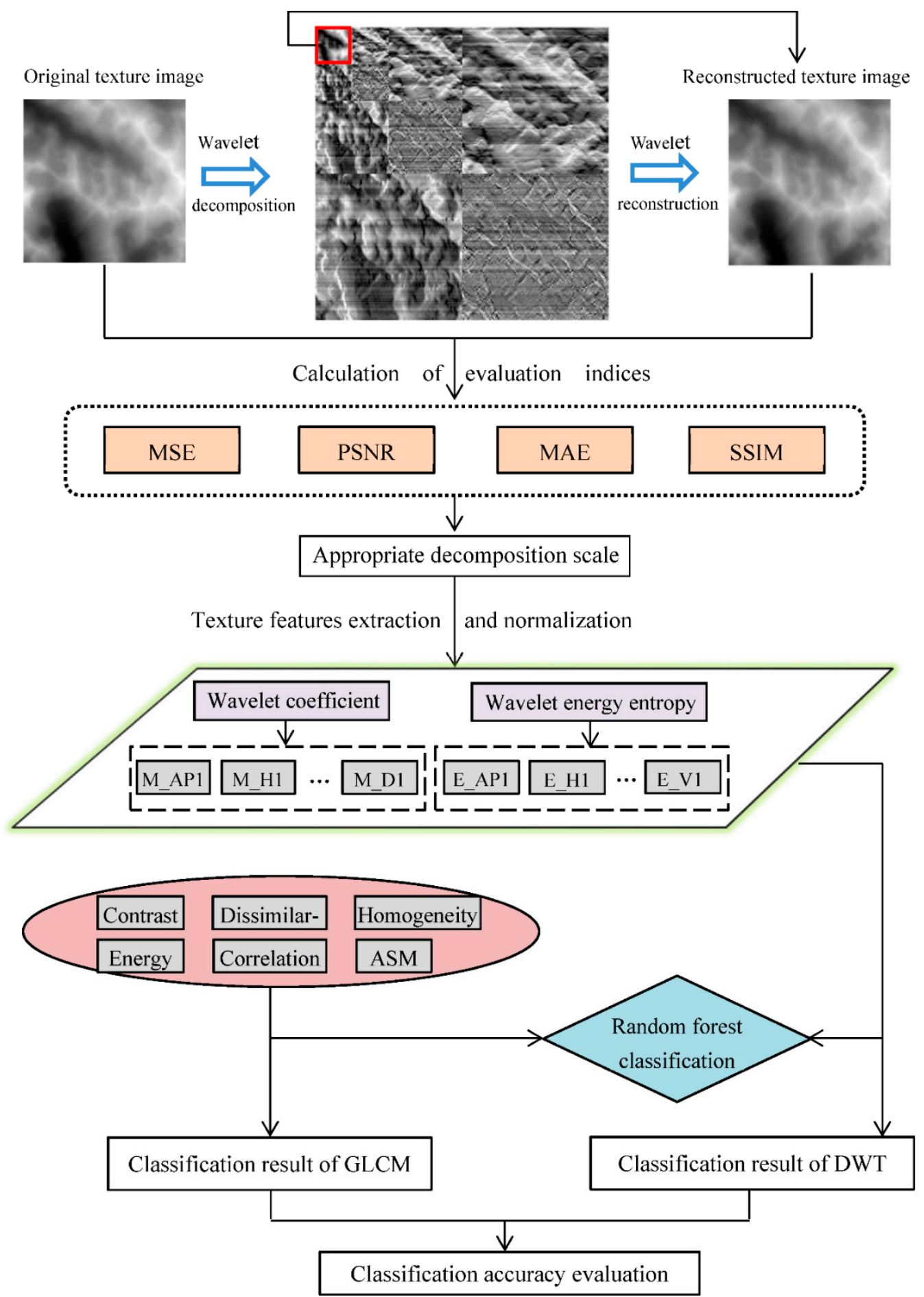

Figure 3. The specific technical route (detailed information of MSE, PSNR, MAE, and SSIM can be seen in Section 2.2.2; discrete wavelet transform (DWT)).

\subsubsection{Texture Mapping}

The texture mapping reflected in DEM images is described by the morphology of different landforms and the significance of texture grayscale. The DEM texture is composed of a primitive arrangement with similar elevation attributes or basic terrain features, such as 
periodicity, directionality, randomness, and scale dependence. Owing to the arrangement of texture primitive, the spatial structure and texture grayscale have the largest intra-class similarity among the same landforms. On the contrary, the largest inter-class differences exist in various landforms (i.e., the cultivated land in the plain is flat, the loess hills are dendritic, the Sichuan Basin is linear, and the sand dunes are honeycomb and long strip (along the wind direction)). The terrain texture is analyzed in different landform types, arguing that using terrain textures for regional-scale landform classification is still necessary. Due to the fact that causes of landforms are difficult to calculate and classify via quantitative indicators, the landform selected in this study are second-order, as shown in Figure 4.

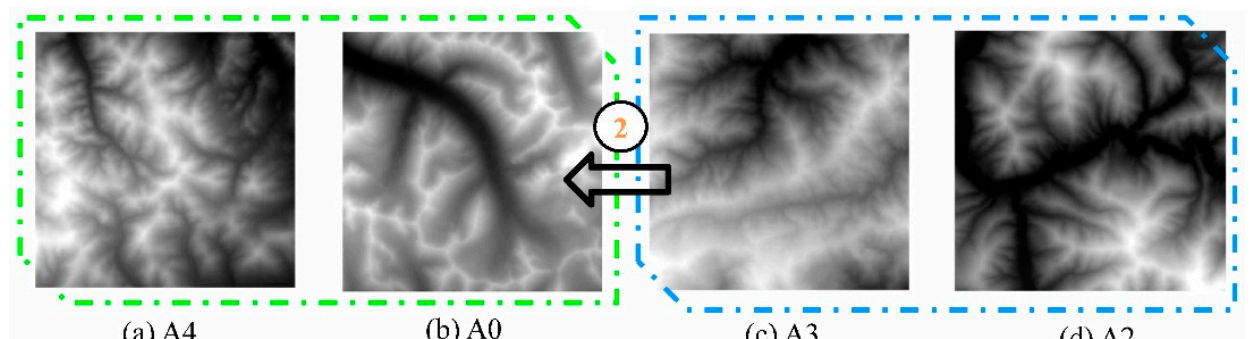

(a) A4

(b) $\mathrm{A} 0$

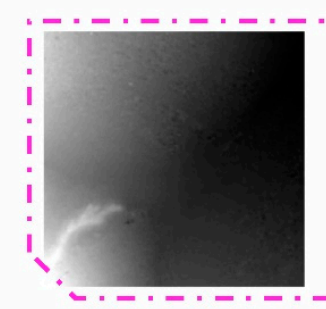

(e) Al

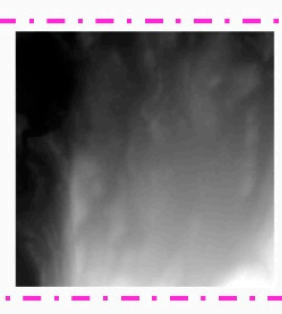

(f) A5 (c) $\mathrm{A} 3$

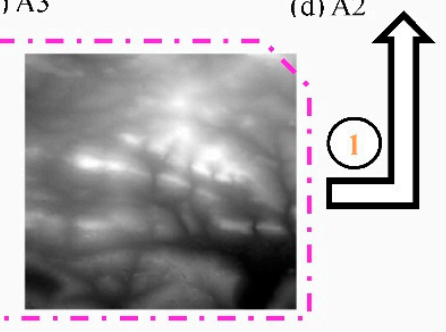

(g) A6

Figure 4. Texture mapping of landform in DEM images. (a) A4: Low relief extremely high mountain; (b) A0: High relief extremely high altitude mountain; (c) A3: Intermediate relief middle mountain; (d) A2: Intermediate relief high mountain; (e) A1: High altitude plain; (f) A5: Extremely high altitude plain; (g) A6: Extremely high altitude high-hill.

The texture morphology is a powerful basis to distinguish different landforms. From the development degree of landforms to observe texture mapping (Figure 4), as the altitude increases, the landform types transit from high altitude plains to high altitude and plain high hills. Moreover, the terrain texture in DEM images gradually changes from a smooth to a strip irregular texture (Figure $4 \mathrm{e}-\mathrm{g}$ ). The texture primitives are arranged regularly, and the texture roughness increases (Figure 4c,d). As the landform relief increases, the self-similarity of gray level in the local area is enhanced, and the texture primitives are significant and continuous with small fragmentation (Figure 4a,b). In general, the structure changes from an irregular shape to a thin branch shape and then, to a round and thick branch shape. Therefore, different texture morphologies are selected to express the corresponding texture features (calculated by quantitative or qualitative indicators). The automatic landform recognition can be achieved using a deep learning training classifier.

\subsubsection{Discrete Wavelet Transform (DWT)}

The spatial domain performs various landform features in the texture image, which is the same in the frequency domain. As the comprehensive effect result of the geologic process, surface morphology can be identified as a superposition of countless mountain waves. In other words, mountain waves in different frequencies are added depending on the weight coefficient. Although relief degrees are diverse, landforms have stabilized the wavelength frequency in local areas [49], and the frequency features and spatial orientations of sub-images vary at different decomposition levels. Consequently, the abstraction and generalization of landform feature information are the core problems to be solved. Given the directionality and spatial structure of terrain texture in frequency spectra, DWT is 
chosen for the terrain texture analysis, considering the excellent characteristics of local time-frequency variation, scale variation, and direction [50].

The texture image intuitive reflects a 2D signal, whose texture features are locally irregular and globally regular. Given that the Haar wavelet can implement a multiscale analysis, thus, it is selected to handle the discrete numerical matrix [51] in this study. First, the Haar transform with four levels are performed on a DEM texture image, causing terrain textures in horizontal, vertical, and diagonal directional decompositions to display regional structure features. The forward decomposition aims to obtain the multiscale landform features quantitatively. Therefore, these calculated texture features are expressed by wavelet coefficients and wavelet energy entropy (the former is the similarity coefficient between the original image and the wavelet basis function, and the latter is the complex expression of the texture energy distribution at different scales). Second, the inverse wavelet reconstruction [52] is designed to remove a series of noise information in high frequency and reconstruct the approximate low-frequency DEM texture image [52]. Finally, the four indices: Mean square error (MSE), peak signal-to-noise ratio (PSNR), mean absolute error (MAE), and structural similarity (SSIM) [53-55] are used as the criteria to evaluate the reconstruction effect of the texture image, and then determine the wavelet decomposition scale. Therefore, the morphology features of landforms are described by the feature vectors. Specific calculations are shown in the following sections. Specifically, MSE represents the difference between stability and pattern decomposition. In other words, the smaller the decomposition effect, the better. The PSNR value explains the degree of image reconstruction and distortion. MAE reflects the actual error of the forecast image. SSIM measures the significance level of the spatial structure in the texture image [56]. All the theoretical analysis results agree well with the terrain texture.

\subsubsection{Classification Method of the RF}

Among the landform classification algorithms, excellent accuracy is exhibited in the RF method $[24,57,58]$ since it can perform well in large datasets, high-dimensional features, importance evaluations, and even default values [59]. Therefore, it is suitable for the high-dimensional texture feature training and landform type classification [60]. In this study, the concrete stages of the RF are as follows: (1) 502 samples are extracted from the DEM data through the sampling technique, and the training set is four-fifth of the original texture samples; (2) Regression trees are established for each training set to generate a forest composed of $N$ decision trees. In the growth process of each tree, $m(m \leq M)$ variables are selected randomly from all the $M$ features $(M=21)$. Conforming to the principle of minimum Gini index, the optimum attributes are confirmed from these $M$ features for internal node branching, in order for each tree to fully grow without an additional data cut operation; (3) The prediction results of $N$ decision trees are gathered, and the landform type of the new texture sample is determined by voting; and (4) One-fifth of the out of bag data, which are probably not selected at each time, are used to estimate the internal error and predict the classification accuracy [61,62]. To achieve better classification accuracy $[63,64]$, a five-fold cross-validation for the experiment is conducted in this study.

\section{Results}

\subsection{Determination of Decomposition Scale}

The DEM texture image is decomposed layer by layer according to the theory of DWT. To ensure the relatively uniform selection of samples for each landform type, the sample size is selected as $256 \times 256$ pixels. Considering that it is a discrete dyadic wavelet transform (DDWT), the zero-padding method was used to deal with obvious splicing boundaries. Theoretically speaking, the total number of pixel rows and columns will be reduced by half after each layer is decomposed, along with the resolution. Considering that 16 pixels can be found when decomposed to the fourth layer, which has a strong ability to macroscopically summarize the landform, only four layers are decomposed in the experiment. The high-frequency diagram of DWT is illustrated in Figure 5. Taking the high 
relief extremely high altitude mountain as a sample example, the law of other landform sample areas is the same.

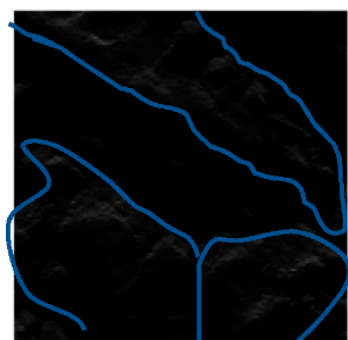

(a) Level 1-Horizontal

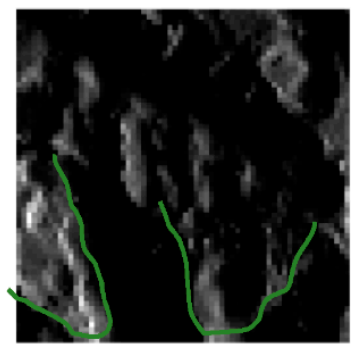

(e) Level 2-Vertical

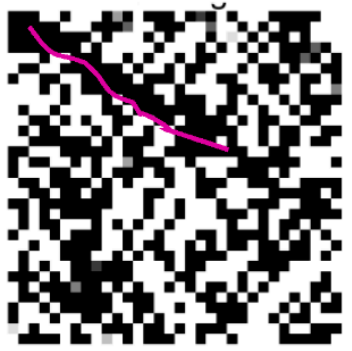

(i) Level 3-Diagonal

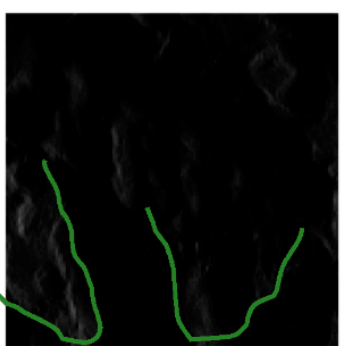

(b) Level 1-Vertical

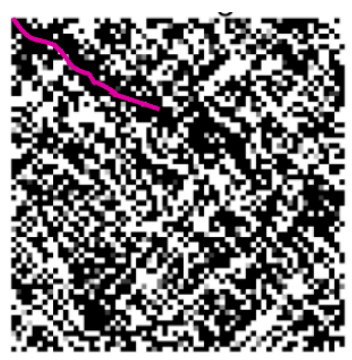

(f) Level 2-Diagonal

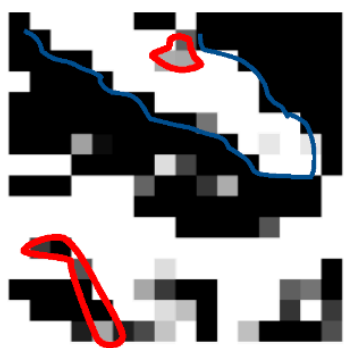

(j) Level 4-Horizontal

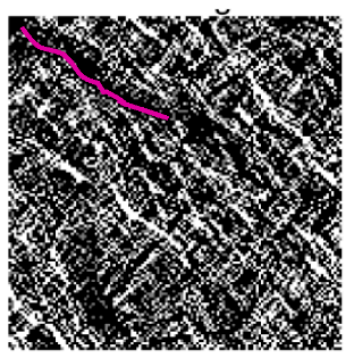

(c) Level 1-Diagonal

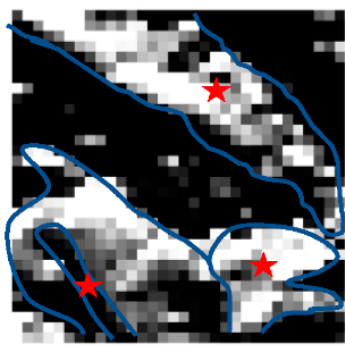

(g) Level 3-Horizontal

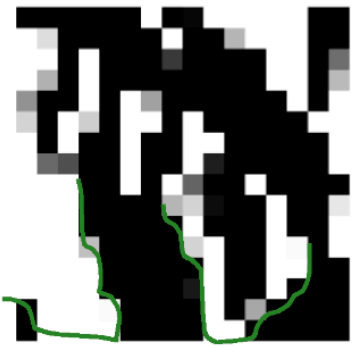

(k) Level 4-Vertical

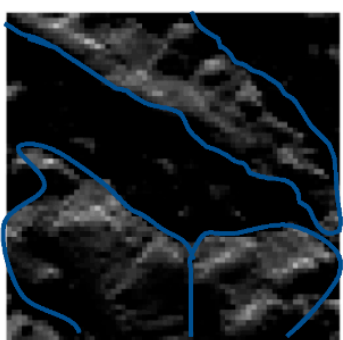

(d) Level 2-Horizontal

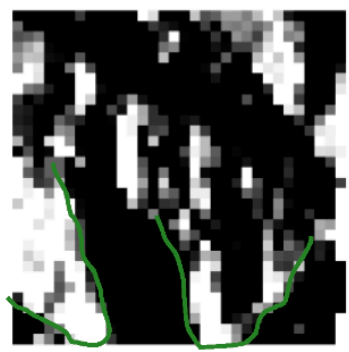

(h) Level 3-Vertical

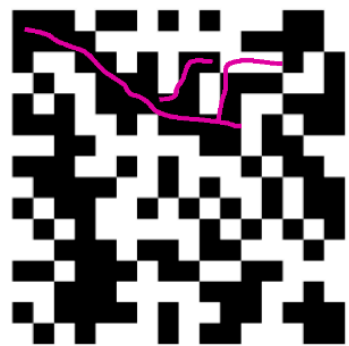

(1) Level 4-Diagonal

Figure 5. (a-1) High-frequency diagram of multiscale wavelet decomposition.

After the high-frequency wavelet decomposition, in either the horizontal or vertical decomposition direction, the rough boundary of landform relief can be seen from level 1, 2, and 3, marked by blue and orange lines. Expressions of gray and white values are adopted to assess the magnitude of landform relief that is higher than the datum level (as the blue line shows), and the dark values indicate depression or the erosion intensity of the landform (as the orange line shows). However, when level 4 is reached, plentiful details of the landform are ignored, only a few pixels are left to maintain the morphology of the landform (as the red circle shows). This condition is inconsistent with the mountainous landform that is composed of several discrete units. Regarding the diagonal image, the valley line can be clearly observed (as the purple line shows), and when the mountain is decomposed to level 4 , the small valley lines extend from the main trunk, which is contrary to the original landform morphology. The wavelet decomposition under level 4 results in geomorphologic distortion and noise redundancy. Therefore, level 3 is confirmed to decompose different landforms. It not only ensures the primary and secondary principles in landform synthesis, but also maintains the continuous and reasonable expression of landform structure.

A better scale to decompose highly structured features of natural images is level 3, in perception. The MSE, PSNR, MAE, and SSIM are used to quantitatively analyze the decomposition scale (level 3) of the texture structure. For the evaluation indices, namely, MSE, PSNR, and MAE, the standard measuring unit is inchoate, whereas the SSIM value ranges from 0 and 1 . Therefore, the values of the first three indices are normalized to 0 
and 1 via $\min / \max$. The $3 \sigma$ principle is used to exclude noise points. The result shows that two noise points in the samples have little influence on the texture analysis. Therefore, the elimination of noise data is ignored. The subsamples of different landforms, whose labels are hand-labeled on the base of the existing landform classification map, are selected randomly to calculate the four values after wavelet reconstruction, as presented in Figure 6. Subsample-29, Subsample-12, Subsample-52, Subsample-47, Subsample-48, Subsample-8, and Subsample-40 belong to sample types A0, A1, A2, A3, A4, A5, and A6, respectively. The law of the other sample groups, which are randomly selected, is the same.
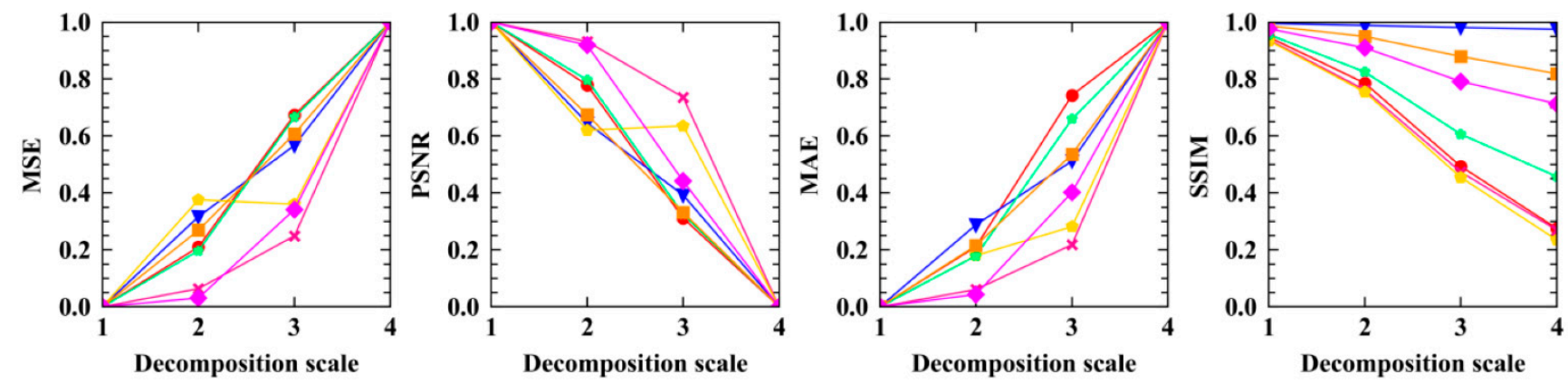

$\rightarrow$ Subsample-29 $\rightarrow$ Subsample-12

Figure 6. Calculation of the texture image evaluation index after wavelet reconstruction.

Specifically, SSIM is the main criterion and the others are the auxiliary criteria. According to the SSIM value, above 0.4 is adopted as the conformity criteria. After determining the preliminary appropriate decomposition scale using the SSIM value, the other three evaluation indices are performed to further check whether the error value between the reconstructed image and original image within the error range is allowed, thereby determining the final appropriate decomposition scale.

In Figure 5, the decomposition level is determined according to the effect of landform relief, and then the objective quantitative indicators are used to evaluate the similarity between the terrain texture of reconstruction and the original image texture. Learning from the meaning of the four indicators in Section 2.2.2, the smaller the MSE and MAE values and the larger the PSNR and SSIM values, the higher the similarity between the terrain texture and the original texture, and the better the effect of the reconstruction. These conditions are close to the appropriate wavelet decomposition scale. Depending on the evaluation criteria of MSE and MAE, the decomposition scale corresponding to the maximum reconstruction error is removed, namely, level 4 (Figure 6). The PSNR and SSIM values are fluctuated at $[0.3,0.9]$. However, when the decomposition is at level 1, the SSIM value is above 0.9 . In other words, the effect of removing detailed landform features while retaining primary structure features is scarce. Therefore, the level 1 wavelet reconstruction is eliminated.

In contrast to decomposition levels 2 and 3, MSE and MAE exhibit a positive growth trend, whereas PSNR and SSIM show a downward trend, which conforms to the law of wavelet reconstruction as the decomposition scale increases. Focusing on the two levels of reconstruction error, MSE and MAE are approximately 0.4, PSNR is above 0.6, and SSIM is approximately 0.8 at level 2. Note that MSE and MAE are approximately 0.7, PSNR is above 0.3 , and SSIM is approximately 0.4 at level 3. From the perspective of error theory, the values between decomposition levels 2 and 3 satisfy the accuracy evaluation of wavelet reconstruction. Although level 2 seems to be good numerically, in essence, the decomposition level is upgraded to a high one, and the resolution is reduced to half of the previous level. Equally, the detailed expression of terrain texture features is reduced innumerably, and the texture structure of the landform is clear, facilitating the analysis of the landform differences. Therefore, the level 3 wavelet reconstruction is chosen through 
the quantitative analysis. Moreover, it increases the number of features in texture analysis, which is convenient for the application of texture in landform classification research.

\subsection{Extraction of Texture Feature Vectors}

According to the appropriate analysis scale, texture feature vectors are determined at the first three decomposition scales, and four directional features can be generated on each decomposition scale. Concretely speaking, 21-dimensional eigenvectors are composed in this study, including the mean values of wavelet coefficient (M_AP1, M_H1, M_V1, M_D1 ... M_D3, $4 \times 3$ dimension) in the total three decomposition scales and wavelet energy entropy in low frequency, horizontal, and vertical directions (E_AP1, E_H1, E_V1 ... E_V3, $3 \times 3$ dimension). AP represents the approximate value of DEM texture image passed by DWT; H, V, and D correspond to the values of horizontal, vertical, and diagonal decompositions; numbers 1, 2, and 3 represent the decomposition scale. Examples of feature extraction with different landforms are presented in Table 1.

Table 1. Wavelet eigenvalues of different landform textures.

\begin{tabular}{|c|c|c|c|c|c|c|c|}
\hline \multirow{2}{*}{ Texture Feature Vector } & \multicolumn{7}{|c|}{ Landform Types } \\
\hline & A0 & A1 & A2 & A3 & A4 & A5 & A6 \\
\hline M_AP1 & 8653.6161 & 9814.7509 & 9476.0397 & 4293.0924 & $10,250.9564$ & $10,037.4176$ & $10,655.9054$ \\
\hline M_H1 & $17,307.2321$ & $19,629.5018$ & $18,952.0795$ & 8586.1848 & $20,501.9129$ & $20,074.8353$ & $21,311.8109$ \\
\hline M_V1 & $34,614.4641$ & $39,259.0037$ & $37,904.1591$ & $17,172.3696$ & $41,003.8259$ & $40,149.6707$ & $42,623.6219$ \\
\hline M_D1 & 0.5911 & -0.1545 & 0.9291 & 1.9932 & -0.3359 & 0.1231 & 0.1576 \\
\hline M_AP2 & -1.3961 & -0.1581 & 0.1683 & 0.6722 & 0.0444 & 0.2361 & 0.2982 \\
\hline M_H2 & 0.0037 & -0.0011 & -0.0012 & 0.0144 & 0.0018 & 0.0029 & -0.0013 \\
\hline M_V2 & 2.4643 & -0.6325 & 3.7229 & 7.8841 & -1.3646 & 0.4441 & 0.6453 \\
\hline M_D2 & -5.5351 & -0.6681 & 0.6022 & 2.6728 & 0.1791 & 0.94843 & 1.2391 \\
\hline M_AP3 & 0.0474 & 0.0001 & -0.0261 & 0.0682 & 0.0144 & 0.0078 & -0.0011 \\
\hline M_H3 & 9.0101 & -2.5345 & 14.8371 & 31.4296 & -5.0751 & 1.8197 & 2.6656 \\
\hline M_V3 & -22.0288 & -2.6971 & 2.6118 & 8.5498 & 0.5437 & 3.7606 & 4.6998 \\
\hline M_D3 & 0.1259 & 0.0491 & -0.1794 & 1.2285 & -0.0776 & 0.0008 & -0.2276 \\
\hline E_AP1 & 99.9902 & 99.9999 & 99.9956 & 99.9844 & 99.9993 & 99.9999 & 99.9996 \\
\hline E_H1 & 0.0005 & 0.0001 & 0.0002 & 0.0009 & 0.0001 & 0.0001 & 0.0001 \\
\hline E_V1 & 0.0021 & 0.0001 & 0.0009 & 0.0034 & 0.0001 & 0.0001 & 0.0001 \\
\hline E_AP2 & 99.9908 & 99.9999 & 99.9961 & 99.9873 & 99.9994 & 99.9999 & 99.9994 \\
\hline E_H2 & 0.0005 & 0.0001 & 0.0002 & 0.0008 & 0.0001 & 0.0001 & 0.0001 \\
\hline E_V2 & 0.0018 & 0.0001 & 0.0008 & 0.0028 & 0.0001 & 0.0001 & 0.0001 \\
\hline E_AP3 & 99.9936 & 99.9999 & 99.9957 & 99.9903 & 99.9993 & 99.9998 & 99.9993 \\
\hline E_H3 & 0.0003 & 0.0001 & 0.0002 & 0.0006 & 0.0001 & 0.0001 & 0.0001 \\
\hline E_V3 & 0.0013 & 0.0001 & 0.0009 & 0.0022 & 0.0001 & 0.0001 & 0.0001 \\
\hline
\end{tabular}

Before the analysis, the extracted texture features are preprocessed, whose values were normalized to 0 and 1 , to remove the influence of the unit and turn it into a dimensionless texture feature vector. A total of 502 samples are generated, and the calculation process is shown in Formula (1).

$$
x^{\prime}=\frac{x_{\max }-x}{x_{\max }-x_{\min }}
$$

where $x$ is the texture eigenvalue of a row vector; $x_{\max }$ and $x_{\min }$ are the maximum and minimum values of the texture eigenvalue in a row vector, respectively.

\subsection{Landform Classification}

Different texture features have significant regional differences in the southeast Tibet Plateau, and similarities can be found among individual types (Figure 7). These similarities are related to the transition characteristics of landforms, but are sufficient to support the classification model as a feature variable. In view of the overfitting that may occur among similar landform types, RF has strong generalization ability and random sampling. The 
model features of random extraction and voting output can effectively alleviate these disadvantages. Furthermore, the $\mathrm{K}$-fold cross validation is performed to optimize the hyperparameters and avoid overfitting.

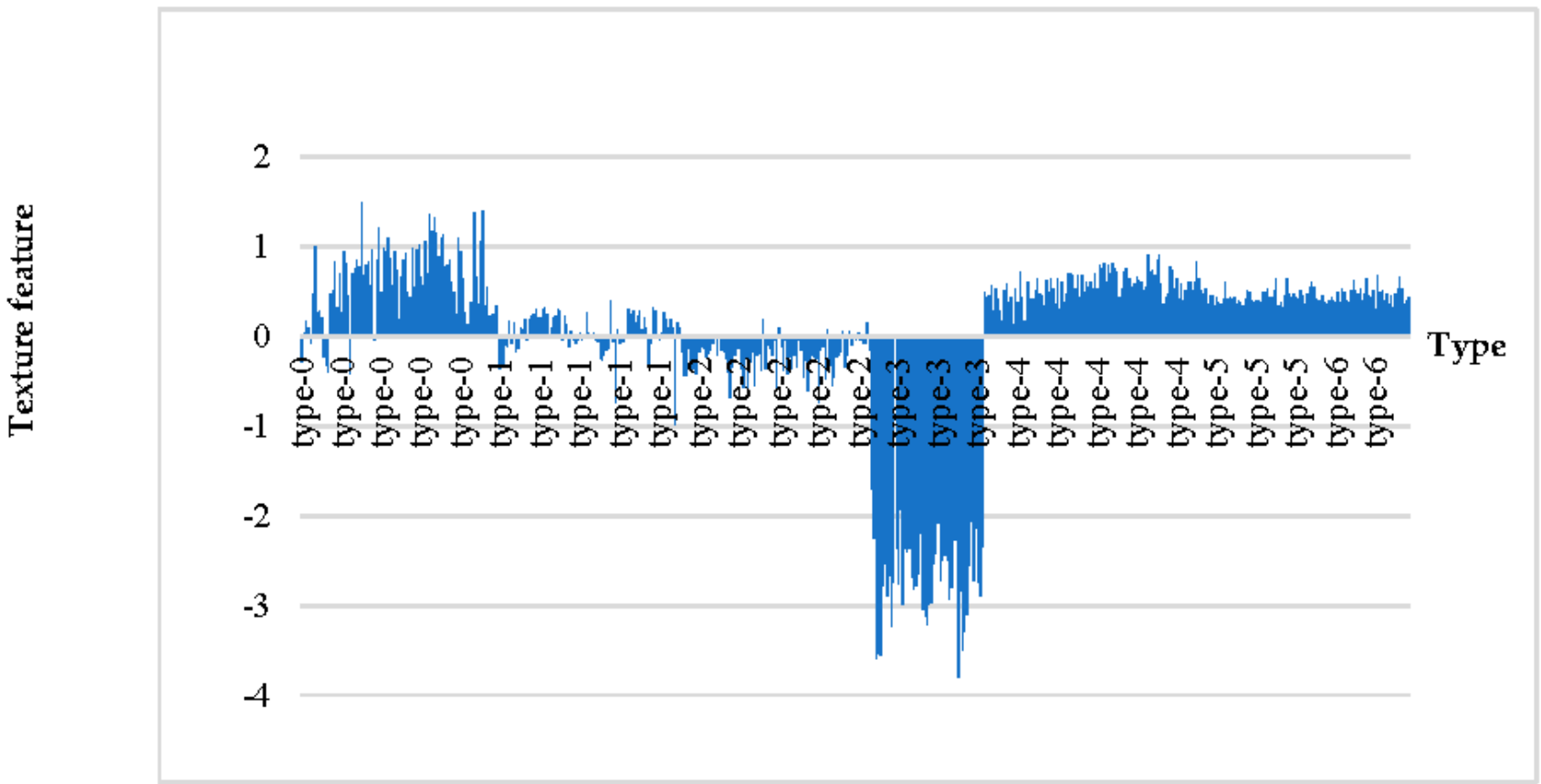

Figure 7. Texture feature in different landforms.

On the basis of the texture feature values extracted in Section 3.2, the landform classification results are achieved using the RF method by learning the differences among different landform types and the homogeneities of similar landform types. The classification process is illustrated in Figure 8.

The 502 samples of landform types are selected in the southwestern Tibet Plateau, and the number of each sample type is shown in Table 2. These landform types are combined with the parameters determined in Figure 8 to construct the RF classifier for sample training. Moreover, $80 \%$ of the total samples are adopted as training samples, and the remaining $20 \%$ serve as test samples to evaluate the effect of training model fitting.

In terms of the DEM image texture, the classification experiment is conducted using the 21-dimension texture feature values of DWT. Finally, the classification accuracy reaches $90 \%$ in seven landform types, and fine classification results are acquired using the RF method.

Table 2. Number of different landform samples.

\begin{tabular}{ccc}
\hline Landform Types & Number of Samples & Area/km \\
\hline High relief extremely high altitude & & \\
mountain (A0) & 85 & 58.9824 \\
High altitude plain (A1) & 86 & 58.9824 \\
Intermediate relief high mountain (A2) & 87 & 58.9824 \\
Intermediate relief middle mountain (A3) & 51 & 58.9824 \\
Low relief extremely high altitude & 98 & 58.9824 \\
mountain (A4) & 45 & 58.9824 \\
Extremely high altitude plain (A5) & 50 & 58.9824 \\
Extremely high altitude high-hill (A6) & & \\
\hline
\end{tabular}




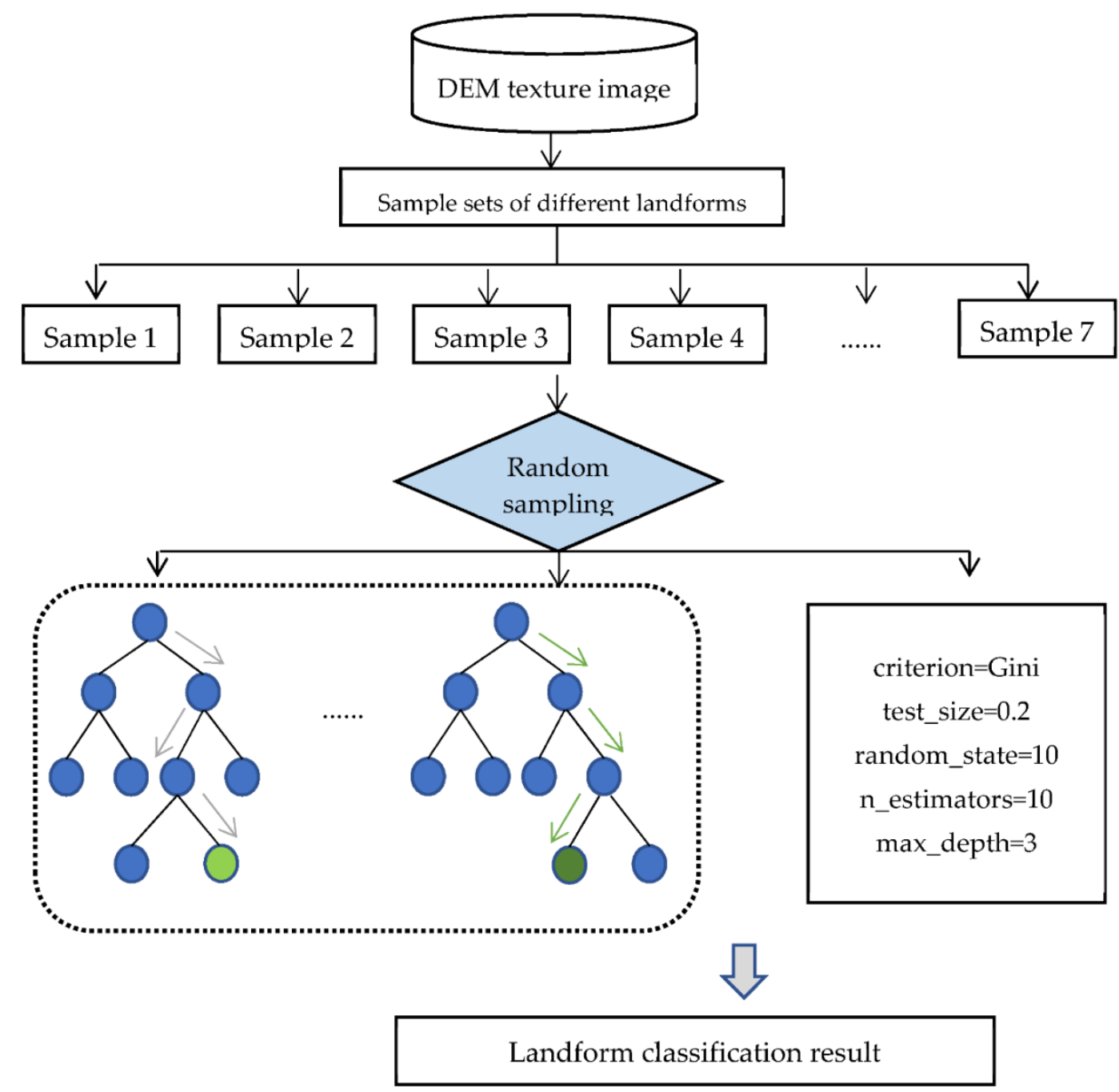

Figure 8. Classification process of landform types based on the RF method.

\section{Discussion}

\subsection{Comparison of Texture Structure between AW3D30 DEM and ASTER GDEM}

The DEM texture image, as an important source of geographical spatial cognition, plays an irreplaceable role in directly reflecting landform structure features. The significance of DEM texture is the criterion to judge the quality of texture structure extraction. Compared with the ASTER GDEM texture images, which present the relief features of pure topographical morphology, the elevation information of AW3D30 covers other than the ground surface, and it is the real expression of surface relief to a large extent, as displayed in Figure 9. The clarity on the terrain texture of AW3D30 is also higher than the ASTER GDEM whether from the macroscopic scale (Figure 9b) or the microscopic scale (Figure 9a). Visually looking at the interpolation results of the ASTER GDEM image, white noise is densely packed in the green box (Figure $9 b$ ). Therefore, the authenticity of the terrain texture is poor in ASTER GDEM data, affecting the calculation of texture feature value. Meanwhile, AW3D30 DEM is less expressed, especially in the landform area with a disordered texture, such as the plain (Figure 9a), where spatial structure textures are obvious from the visual perception and image noise points in the orange box [39]. As the expression of texture structure reflected in Figure 9a, the width of the AW3D30 DEM texture is larger than that of ASTER GDEM in the mountainous area. The AW3D30 DEM texture in the plain area seems as a flame, whereas ASTER GDEM shows a scattered-patch texture. In fact, a gradual transition characteristic is displayed in the spatial pattern among the landform 
types, and the AW3D30 DEM texture in the plain area is displayed intuitively in relation to this kind of property (color transition from black, to gray, and to white). Rather, the point texture of ASTER GDEM is adverse to the analysis of macroscopic landform features. Therefore, selecting the suitable data source is critically important in texture structure analysis. Given that AW3D30 DEM connects the terrain texture and geometric form, and DWT acquires multiscale texture features, the internal landform structure and the external surface sediment transfer and evolution are expected to be further revealed. Ultimately, a nonlinear self-organizing dynamic evolution system with the combination of material causes and morphological mechanisms can be realized.

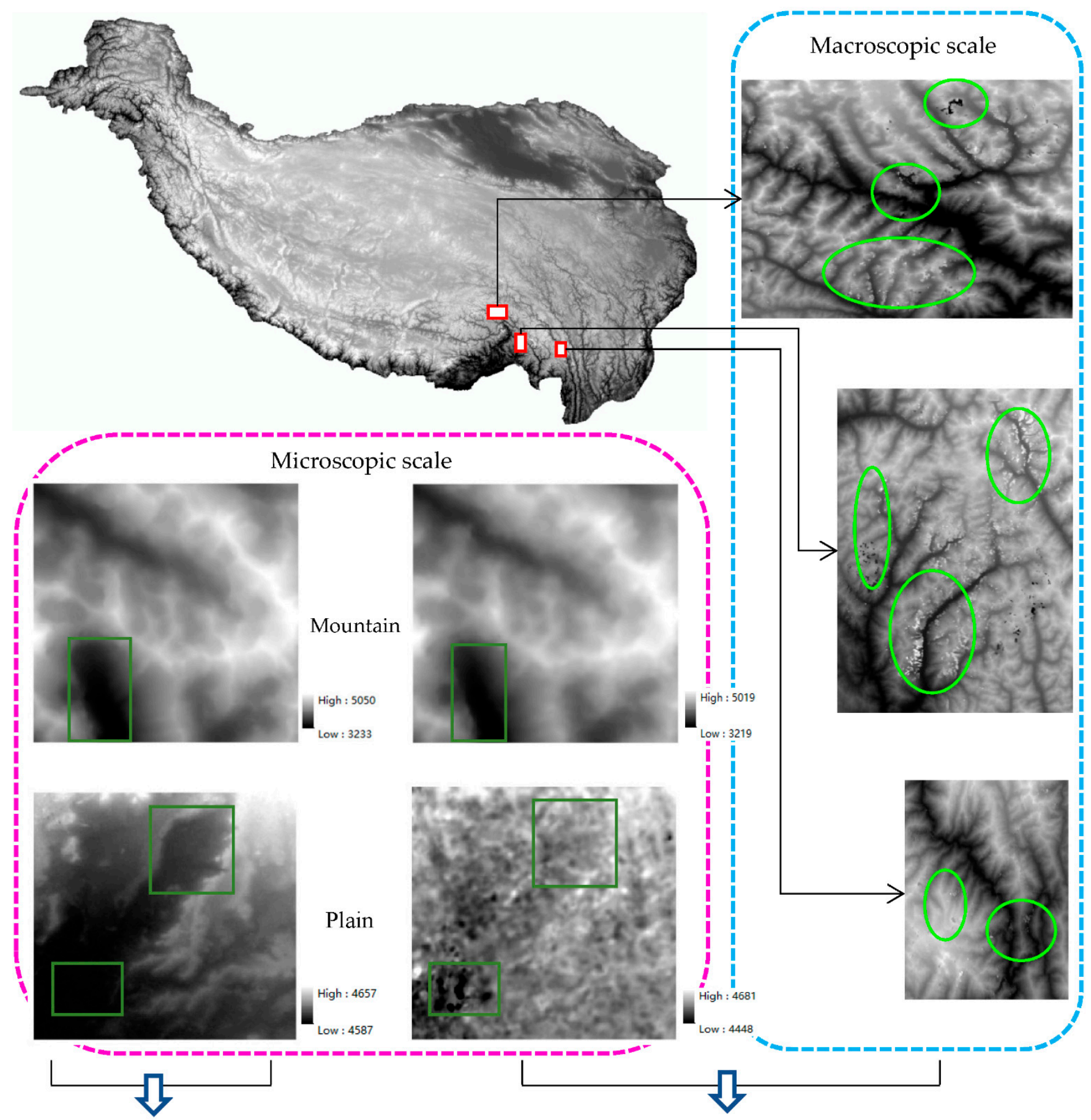

Figure 9. Detailed comparisons of AW3D30 DEM and ASTER GDEM texture images. (a) AW3D30 texture image; (b) ASTER GDEM texture image. 


\subsection{Comparison of Texture Feature Extraction between DWT and GLCM}

Three high-frequency texture and low-frequency approximate texture images are obtained using the Haar wavelet after a one-layer decomposition. Information on the mutation position, structure arrangement, image details, and interference noise is fastened on the high-frequency image, whereas the place where the gray level is located gently changes in the original texture image and focuses on the low-frequency image. The micro and macro landform features are preserved via DWT. Conversely, the multiscale texture feature extraction of the GLCM method requires data preprocessing, such as resampling into different resolution texture images or discussing second-order statistical texture features under different analysis windows. Only micro grayscale texture images are derived from GLCM in four directions $\left(0,45,90\right.$, and $\left.135^{\circ}\right)$. The mean value is regarded as the texture feature in the region. Aiming at the frequency domain of image processing, DWT is a global analysis method that complements the spatial and frequency domains. One thing that can be obtained in the spatial domain is the statistical texture feature values. In the frequency domain, the detailed texture structure feature images, which map the regional differences of landforms, can be obtained. GLCM is a probability statistical analysis method of pixel gray level in the spatial domain. However, it fails to resolve obvious features of spatial structure distribution of terrain texture primitives. In general, whether from the visual perception, which interprets the texture primitive features of spatial structure distribution (i.e., the orientation and period of texture primitives) or achieves the landform classification using the machine learning method to train texture features that are processed by normalization, DWT obtains texture features and has more advantages than GLCM due to the multi-perspective texture analysis. Moreover, the classification accuracy has been improved to a certain extent by approximately $11.8 \%$, as presented in Table 3 . An improved landform classification effect of DWT with 21 dimension features was obtained than with 24 dimension features of the GLCM method, showing that lesser texture features are adopted enough to express the landform features. In addition, two parameters are used for classification, which have more comprehensive and representative significance than the six parameters of GLCM, especially in the course of refining extraction.

Table 3. Results of classification accuracy using the DWT and GLCM for the texture features extraction among landforms.

\begin{tabular}{ccc}
\hline Texture Analysis Method & Feature Parameter (Extraction Number) & Landform Classification Accuracy (\%) \\
\hline DWT & Wavelet coefficient (12); Wavelet energy entropy (9) & 91.09 \\
GLCM & Contrast (4); Dissimilarity (4); Homogeneity (4); & 79.21 \\
\hline
\end{tabular}

On account of the RF method, the classification results of different landforms are calculated by the confusion matrix, and the performance of RF is analyzed, as shown in Table 4. The result indicates that the GLCM method presents a huge amount of misclassification in the extremely high altitude plains and high hills, which are misclassified to the low relief extremely high mountain. This misclassification may be due to the classification ability of extracted texture features, in which these high-altitude regions are too poor to distinguish the differences among landforms. On the contrary, DWT has a balanced improvement in user accuracy (UA) and producer accuracy (PA) in landform classification results, which are above $65 \%$ in each type. Furthermore, drawing on the spatial significance of landform structures, the range of each terrain texture is expressed as $58.9824 \mathrm{~km}$. Compared with the GLCM on this spatial scale, the PA of the DWT is increased by more than $67 \%$ on A3 (intermediate relief middle mountain), A5 (extremely high altitude plain), and A6 (extremely high altitude high-hill). In sum, the texture analysis method based on DWT can obtain superior performance in the classification effect. 
Table 4. The PA and UA of classification of different landforms.

\begin{tabular}{ccccc}
\hline \multirow{2}{*}{ Landforms } & \multicolumn{3}{c}{ DWT } & \multicolumn{2}{c}{ GLCM } \\
\cline { 2 - 5 } & PA (\%) & UA (\%) & PA (\%) & UA (\%) \\
\hline A0 & 100 & 100 & 100 & 100 \\
A1 & 94.1 & 94.1 & 100 & 100 \\
A2 & 95 & 100 & 100 & 100 \\
A3 & 100 & 100 & 32.3 & 100 \\
A4 & 83.3 & 88.2 & 100 & 100 \\
A5 & 100 & 77.8 & 0 & 0 \\
A6 & 66.7 & 72.7 & 0 & 0 \\
\hline
\end{tabular}

\subsection{Texture Structure Analysis on the Scale Characterization among Different Landforms}

The dimensional characterization of texture structure is embodied in texture primitives, which correspond to the terrain textures displayed by the landform structures in the Tibet Plateau. These primitives are diverse under the conditions of different analysis scales. In the aspect of research levels, a multiresolution DEM texture image is used to analyze regional spatial landform distribution patterns from a macro perspective, explore local landform structure from a micro perspective, and study the surface relief and profile from diagonal decompositions, that both enhance the comprehensive analysis of multidimensional landform features. As seen from the SSIM value of the texture (Figure 6), we can gain several structure features: (1) Directed at different landform types, high altitude plains $>$ extremely high altitude plains $>$ extremely high altitude high-hills $>$ low relief extremely high altitude mountains $>$ high relief extremely high altitude mountains $>$ intermediate relief high mountains $>$ Intermediate relief middle mountains. The results reveal that a certain correlation exists between landform relief and structural similarity. (2) In the field of scale research, the variation trend of the texture structure in the plain and hilly areas is stable, whereas the landforms (high mountains and middle mountains) are greatly affected by the scale. The larger the decomposition scale, the more obvious the main texture structure, the smaller the similarity with the surrounding pixels, and the higher the contrast. Therefore, the regional spatial distribution pattern of mountainous structures is increasingly prominent, showing that the decomposition scale is related to the complexity of texture structure of the landform types. (3) Speaking from the fluctuation range of SSIM at different scales, high and middle mountainous areas $>$ plain and hilly areas, reflects that the landforms of the plains and hilly areas have a disorganized texture without direction, whereas other mountainous landforms do not have this texture, which has the distinct expression of terrain texture features. In conclusion, the structural decomposition with different scales heightens the differences among landform types. Therefore, a better classification result can be obtained.

\subsection{Features Analysis of Landform Spatial Structure Using Different Texture Methods}

As a basic geometric quantity for describing the surface undulation, elevation is the direct source of grayscale mapping in the terrain texture. Therefore, the difference variation of the regional landform structure can be analyzed in line with the adjacent texture grayscale. Two texture analysis methods, termed GLCM and DWT, are compared.

In landform type A0 (high relief extremely high altitude mountain), dissimilarity (DIS) (GLCM measure) is selected to reflect the gray difference and analyze the landform spatial structure. Figure 10a-d shows the texture features of GLCM-DIS in different directions. Whether in horizontal (Figure 10a) or in vertical (Figure 10c), the huge gray differences are in the lower left corner, where the heterogeneity in elevation is greater than that of other locations, revealing a great variation of landform relief. At the left diagonal of $45^{\circ}$, the great heterogeneity is a claw-like (yellow line) area, highlighting that the valleys and the surrounding mountains are in sharp contrast. Two long strips (yellow line) along with great heterogeneity appear in the right diagonal $135^{\circ}$. Therefore, the spatial structure of the gully landform is remarkable. 


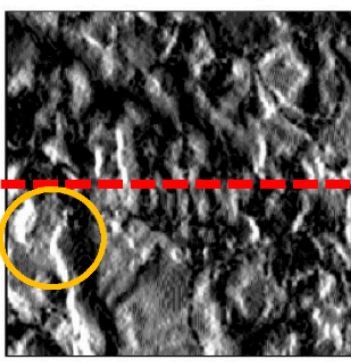

(a) $\mathrm{GLCM}-0^{\circ}$

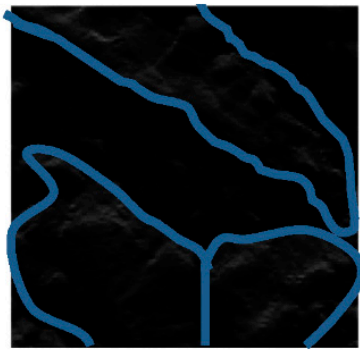

(e) Level 1-Horizontal

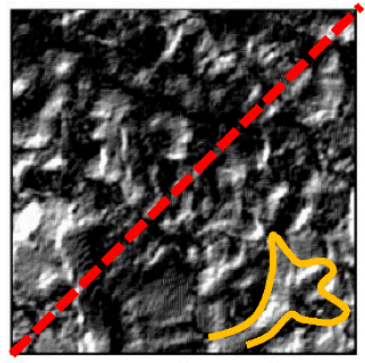

(b) GLCM-45

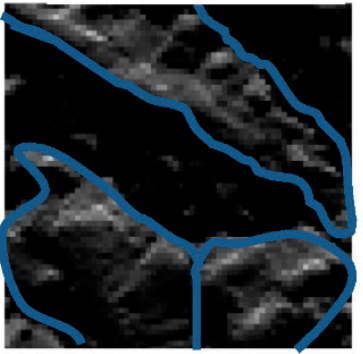

(f) Level 2-Horizontal

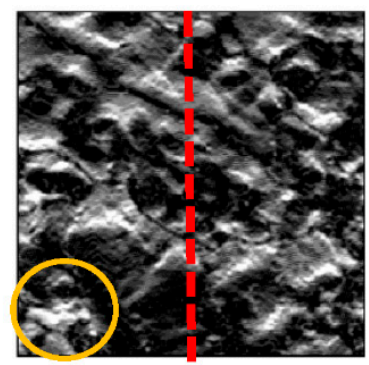

(c) GLCM $-90^{\circ}$

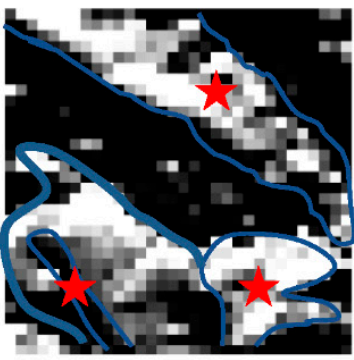

(g) Level 3-Horizontal

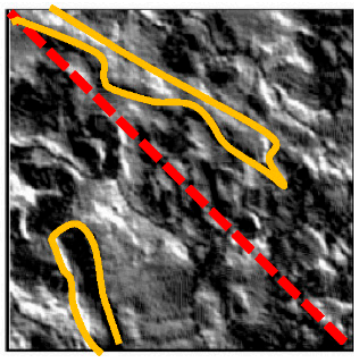

(d) GLCM-135

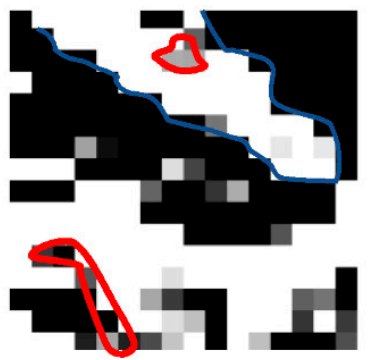

(h) Level 4-Horizontal

Figure 10. Landform spatial structure features of different texture analysis methods. (a) $\mathrm{GLCM}-0^{\circ}$; (b) $\mathrm{GLCM}-45^{\circ}$;
(c) GLCM-90;
(d) GLCM-135;
(e) Level 1-Horizontal;
(f) Level 2-Horizontal;
(g) Level 3-Horizontal;

(h) Level 4-Horizontal.

Focusing on the DWT texture analysis (Figure 10e-h), the result shows that the landform spatial structure indicates clear priorities at different decomposition scales. At levels 1 and 2, landforms can only be regarded as porphyritic agglomeration distribution. At level 3 (the appropriate decomposition scale in Section 3.1), landforms exhibit plate, strip, and plate structures (as the red star displays). A fist-like shape at the top, lower left, and lower right are also shown. However, the landform structures are distorted and rough, with only a strip valley at the lower right by the level 4 decomposition. The multiscale landform structure in this study is composed of visual contour and mountain slope. The spatial structure is scale dependent, meaning that geospatial cognition about the same spatial pattern, such as spatial convergence and dispersion, is discrepant under different scales. In other words, the recombination or manifestation of spatial structure changed with scale.

Different from the GLCM method in the spatial structure analysis, which calculates the texture difference via different directions, landform structures are suggested as inconsistent in a protruding point. Given that a complete landform spatial structure is in trouble by one calculation, DWT is a comprehensive method, and the spatial size of landform structure varies at each decomposition scale. Through the appropriate decomposition scale, the spatial structure characteristics of landforms can be completely expressed. A low decomposition scale determines the macro structure features, whereas a high decomposition scale determines the micro structure features, which is effective in depicting the valley structures. In summary, the texture analysis method based on DWT has good performance for local landform spatial structures that are efficient and realistic.

\section{Conclusions}

DWT is an important method for multiscale structure decomposition, and DEM is a key data source for analyzing the landform texture. Using a DEM texture image to extract terrain texture structure and feature vector through multilevel DWT can realize landform classification. Additionally, DWT can perform well in the analysis of the spatial structure and anisotropy of geographic elements at different scales. The main results and conclusions are as follows: 
(1) On the basis of the AW3D30 texture image, the DWT method is employed to obtain the local structural features of landforms in low and high frequencies with different decomposition scales. The fine texture structure of a landform is depicted at a low decomposition level. Nevertheless, the coarse texture is stored at a high decomposition level. In the end, the features of the main texture spatial distribution account for the landform direction.

(2) The appropriate decomposition scale is confirmed using the image evaluation indices of the wavelet reconstruction. Meanwhile, the wavelet coefficients and wavelet energy entropy of the texture are calculated on this scale. Furthermore, the second-order statistical features of six texture measures are extracted using the GLCM method, which makes a full precondition for the landform classification.

(3) Given the different texture feature values and the number of samples, the RF method is adopted to classify landforms. Approximately $80 \%$ of the total features are selected as training samples to fit the classification model, and the other $20 \%$ are used as test samples to evaluate the classification accuracy. The texture method based on DWT, which acquires high classification accuracy with less texture feature dimension, is superior to GLCM in analyzing the gray spatial correlation of the texture structure. A concrete change suggests that the PA of the DWT is increased by more than $67 \%$ on A3 (intermediate relief middle mountain), A5 (extremely high altitude plain), and A6 (extremely high altitude high-hill). The overall accuracy was improved by approximately $11.8 \%$.

On the basis of the basic features of terrain texture, the analysis of macro landform features is realized, the classification and recognition of multi-class landform types are carried out, and the basic relief forms and the spatial differentiation features of landform development are quantitatively analyzed. The limitation of this study lies in the lack of the optimum analysis window for landform units under different resolutions. In other words, the sample size analysis of the texture image is lacking. Given that the presentation details of the landform are heterogeneous with different scales, including the considerable abrupt and gradual change, the texture structure is insufficient to adequately express integrity, which can be the focus of future studies. To improve classification accuracy, statistical features can be combined with structural features to carry out the landform classification necessary for deep learning.

Author Contributions: Conceptualization, Hongchun Zhu; methodology, Yuexue $\mathrm{Xu}$; software, Yuexue $\mathrm{Xu}$; validation, Yuexue $\mathrm{Xu}$, Jinyu Li, and Shengjia Zhang; investigation, Haiying Liu; resources, Hongchun $\mathrm{Zhu}$ and Haiying Liu; draft manuscript preparation, Yuexue $\mathrm{Xu}$; comments and suggestion, Hongchun Zhu and Jinyu Li; final manuscript, Yuexue $\mathrm{Xu}$, Shengjia Zhang, and Jinyu Li; funding acquisition, Hongchun Zhu. All authors have read and agreed to the published version of the manuscript.

Funding: This work was supported by the auspices of the National Natural Science Foundation of China (grant nos. 41930102, 41971339, and 41771423) and SDUST Research Fund (no. 2019TDJH103).

Institutional Review Board Statement: Not applicable.

Informed Consent Statement: Not applicable.

Data Availability Statement: The data presented in this study are available on request from the corresponding author.

Acknowledgments: The authors would like to thank the following institutions for their kind assistance with this research: Japan Aerospace Research and Development Agency (https:/ / www.eorc. jaxa.jp/ALOS/en/aw3d30/data/index.htm, accessed on 6 October 2020) and Geospatial Data Cloud (http:/ / www.gscloud.cn/, accessed on 18 October 2020) for providing the DEM data, the National Tibetan Plateau Data Center (http:/ / data.tpdc.ac.cn, accessed on 20 June 2021) for providing the data set of the shapefile.

Conflicts of Interest: The authors declare no conflict of interest. 


\section{References}

1. Pain, C. Mapping of landforms from landsat imagery: An example from eastern new south wales, australia. Remote Sens. Environ. 1985, 17, 55-65. [CrossRef]

2. Zhang, H.; Zhou, C.; Lv, G.; Wu, Z.; Lu, F.; Wang, J.; Yue, T.; Luo, J.; Ge, Y.; Qin, C. The Connotation and Inher-itance of Geo-information Tupu. J. Geo Inf. Sci. 2020, 22, 653-661. [CrossRef]

3. Evans, I.S. Geomorphometry and landform mapping: What is a landform? Geomorphology 2012, 137, 94-106. [CrossRef]

4. Xiong, L.; Tang, G.; Yang, X.; Li, F. Geomorphology-oriented digital terrain analysis: Progress and perspectives. J. Geogr. Sci. 2021, 31, 456-476. [CrossRef]

5. Liu, K.; Tang, G.; Tao, Y.; Jiang, S. GLCM Based Quantitative Analysis of Terrain Texture from DEMs. J. Geo Inf. Sci. 2012, 14, 751-760. [CrossRef]

6. Tang, G.; Li, F.; Liu, X.; Long, Y.; Yang, X. Research on the slope spectrum of the Loess Plateau. Sci. China Ser. E Technol. Sci. 2008, 51, 175-185. [CrossRef]

7. Liu, S.; Li, F.; Jiang, R.; Chang, R.; Liu, W. A Method of Loess Landform Automatic Recognition Based on Slope Spectrum. J. Geo Inf. Sci. 2015, 17, 1234-1242. [CrossRef]

8. Grohmann, C.H.; Smith, M.J.; Riccomini, C. Multiscale Analysis of Topographic Surface Roughness in the Midland Valley, Scotland. IEEE Trans. Geosci. Remote Sens. 2011, 49, 1200-1213. [CrossRef]

9. Piloyan, A.; Konecny, M. Semi-Automated Classification of Landform Elements in Armenia Based on SRTM DEM using K-Means Unsupervised Classification. Quaest. Geogr. 2017, 36, 93-103. [CrossRef]

10. Shang, R.; Peng, P.; Shang, F.; Jiao, L.; Shen, Y.; Stolkin, R. Semantic Segmentation for SAR Image Based on Texture Complexity Analysis and Key Superpixels. Remote Sens. 2020, 12, 2141. [CrossRef]

11. Trevisani, S.; Rocca, M. MAD: Robust image texture analysis for applications in high resolution geomorphometry. Comput. Geosci. 2015, 81, 78-92. [CrossRef]

12. Li, B.; Ling, Z.; Zhang, J.; Chen, J.; Wu, Z.; Ni, Y.; Zhao, H. Texture descriptions of lunar surface derived from LOLA data: Kilometer-scale roughness and entropy maps. Planet. Space Sci. 2015, 117, 303-311. [CrossRef]

13. Iwahashi, J.; Kamiya, I.; Matsuoka, M.; Yamazaki, D. Correction to: Global terrain classification using $280 \mathrm{~m}$ DEMs: Segmentation, clustering, and reclassification. Prog. Earth Planet. Sci. 2018, 5, 13. [CrossRef]

14. Kupidura, P. The Comparison of Different Methods of Texture Analysis for Their Efficacy for Land Use Classification in Satellite Imagery. Remote Sens. 2019, 11, 1233. [CrossRef]

15. Trevisani, S.; Cavalli, M.; Marchi, L. Surface texture analysis of a high-resolution DTM: Interpreting an alpine basin. Geomorpholory 2012, 161-162, 26-39. [CrossRef]

16. Iwahashi, J.; Yamazaki, D.; Nakano, T.; Endo, R. Correction to: Classification of topography for ground vulnerability assessment of alluvial plains and mountains of Japan using $30 \mathrm{~m}$ DEM. Prog. Earth Planet. Sci. 2021, 8, 1-2. [CrossRef]

17. Du, L.; You, X.; Li, K.; Meng, L.; Cheng, G.; Xiong, L.; Wang, G. Multi-modal deep learning for landform recognition. ISPRS J. Photogramm. Remote Sens. 2019, 158, 63-75. [CrossRef]

18. Li, S.; Xiong, L.; Tang, G.; Strobl, J. Deep learning-based approach for landform classification from integrated data sources of digital elevation model and imagery. Geomorphology 2020, 354, 107045. [CrossRef]

19. Randen, T.; Husøy, J.H. Filtering for texture classification: A comparative study. IEEE Trans. Pattern Anal. Mach. Intell. 1999, 21, 291-310. [CrossRef]

20. Na, J.; Ding, H.; Zhao, W.; Liu, K.; Tang, G.; Pfeifer, N. Object-based large-scale terrain classification combined with segmentation optimization and terrain features: A case study in China. Trans. GIS 2021. [CrossRef]

21. Lan, Z.; Liu, Y. Study on Multi-Scale Window Determination for GLCM Texture Description in High-Resolution Remote Sensing Image Geo-Analysis Supported by GIS and Domain Knowledge. ISPRS Int. J. Geo Inf. 2018, 7, 175. [CrossRef]

22. Haralick, R.M.; Shanmugam, K.; Dinstein, I. Textural Features for Image Classification. IEEE Trans. Syst. Man Cybern. 1973, SMC-3, 610-621. [CrossRef]

23. Zhao, H.; Fang, X.; Ding, H.; Josef, S.; Xiong, L.; Na, J.; Tang, G. Extraction of Terraces on the Loess Plateau from High-Resolution DEMs and Imagery Utilizing Object-Based Image Analysis. ISPRS Int. J. Geo Inf. 2017, 6, 157. [CrossRef]

24. Zhao, W.-F.; Xiong, L.-Y.; Ding, H.; Tang, G.-A. Automatic recognition of loess landforms using Random Forest method. J. Mt. Sci. 2017, 14, 885-897. [CrossRef]

25. Shumack, S.; Hesse, P.; Farebrother, W. Deep learning for dune pattern mapping with the AW3D30 global surface model. Earth Surf. Process. Landf. 2020, 45, 2417-2431. [CrossRef]

26. Lucieer, A.; Stein, A. Texture-based landform segmentation of LiDAR imagery. Int. J. Appl. Earth Obs. Geoinf. 2005, 6, 261-270. [CrossRef]

27. Wilhelm, T.; Geis, M.; Püttschneider, J.; Sievernich, T.; Weber, T.; Wohlfarth, K.; Wöhler, C. DoMars16k: A Diverse Dataset for Weakly Supervised Geomorphologic Analysis on Mars. Remote Sens. 2020, 12, 3981. [CrossRef]

28. Bugnicourt, P.; Guitet, S.; Santos, V.F.; Blanc, L.; Sotta, E.D.; Barbier, N.; Couteron, P. Using textural analysis for regional landform and landscape mapping, Eastern Guiana Shield. Geomorphology 2018, 317, 23-44. [CrossRef]

29. Wu, J.; Fang, J.; Tian, J. Terrain Representation and Distinguishing Ability of Roughness Algorithms Based on DEM with Different Resolutions. ISPRS Int. J. Geo Inf. 2019, 8, 180. [CrossRef] 
30. Chowdhury, P.R.; Deshmukh, B.; Goswami, A.; Prasad, S.S. Neural Network Based Dunal Landform Mapping from Multispectral Images Using Texture Features. IEEE J. Sel. Top. Appl. Earth Obs. Remote Sens. 2010, 4, 171-184. [CrossRef]

31. Soille, P. Morphological Image Analysis: Principles and Applications; Springer Science \& Business Media: Berlin/Heidelberg, Germany, 2013.

32. Chellappa, R.; Chatterjee, S. Classification of textures using Gaussian Markov random fields. IEEE Trans. Acoust. Speech Signal Process. 1985, 33, 959-963. [CrossRef]

33. Aujol, J.-F.; Gilboa, G.; Chan, T.; Osher, S. Structure-Texture Image Decomposition-Modeling, Algorithms, and Parameter Selection. Int. J. Comput. Vis. 2006, 67, 111-136. [CrossRef]

34. Nikolakopoulos, K.G. Accuracy assessment of ALOS AW3D30 DSM and comparison to ALOS PRISM DSM created with classical photogrammetric techniques. Eur. J. Remote Sens. 2020, 53, 39-52. [CrossRef]

35. Sun, W.; Wang, R. Fully Convolutional Networks for Semantic Segmentation of Very High Resolution Remotely Sensed Images Combined With DSM. IEEE Geosci. Remote Sens. Lett. 2018, 15, 474-478. [CrossRef]

36. Gangodagamage, C.; Foufoula-Georgiou, E.; Brumby, S.P.; Chartrand, R.; Koltunov, A.; Liu, D.; Cai, M.; Ustin, S.L. WaveletCompressed Representation of Landscapes for Hydrologic and Geomorphologic Applications. IEEE Geosci. Remote Sens. Lett. 2016, 13, 480-484. [CrossRef]

37. Doglioni, A.; Simeone, V. Geomorphometric analysis based on discrete wavelet transform. Environ. Earth Sci. 2013, 71, 3095-3108. [CrossRef]

38. Liu, C.; Fang, J.; Liu, Y.; Lu, Y. Field terrain recognition based on extreme learning theory using wavelet and texture features. Adv. Mech. Eng. 2018, 10, 1-10. [CrossRef]

39. Li, H.; Zhao, J. Evaluation of the Newly Released Worldwide AW3D30 DEM Over Typical Landforms of China Using Two Global DEMs and ICESat/GLAS Data. IEEE J. Sel. Top. Appl. Earth Obs. Remote Sens. 2018, 11, 4430-4440. [CrossRef]

40. Zhang, G.; Yao, T.; Xie, H.; Kang, S.; Lei, Y. Increased mass over the Tibetan Plateau: From lakes or glaciers? Geophys. Res. Lett. 2013, 40, 2125-2130. [CrossRef]

41. Zhang, G. Dataset of river basins map over the TP (2016). Natl. Tibet. Plateau Data Cent. 2019. [CrossRef]

42. Zhao, S.; Cheng, W.; Chai, H.; Qiao, Y. Research on the information extraction method of periglacial geomorphology on the Qinghai-Tibet Plateau based on remote sensing and SRTM: A case study of 1: 1,000,000 Lhasa map sheet(H46). Geogr. Res. 2007, 26, 1175-1185. [CrossRef]

43. Chang, Z.; Sun, W.; Wang, J.; Zhang, Z. Object-oriented Method Based on Classification of Geomorphic Type in the Tibet Plateau and Adjacent Regions. Mt. Res. 2017, 35, 1-8. [CrossRef]

44. Zhou, C.; Cheng, W.; Qian, J.; Li, B.; Zhang, B. Research on the Classification System of Digital Land Geomorphology of 1: 1,000,000 in China. J. Geo Inf. Sci. 2009, 11, 707-724. [CrossRef]

45. Tao, Y.; Wang, C.; Jiang, S. A new method on terrain texture characteristics extraction based on improved dual-tree complex wavelet transform. Geogr. Geo Inf. Sci. 2017, 33, 47-50. [CrossRef]

46. Karimzadeh, S.; Feizizadeh, B.; Matsuoka, M. DEM-Based Vs30 Map and Terrain Surface Classification in Nationwide Scale-A Case Study in Iran. ISPRS Int. J. Geo Inf. 2019, 8, 537. [CrossRef]

47. Tadono, T.; Nagai, H.; Ishida, H.; Oda, F.; Naito, S.; Minakawa, K.; Iwamoto, H. Generation of the 30 M-Mesh Global Digital Surface Model by Alos Prism. Int. Arch. Photogramm. Remote Sens. Spat. Inf. Sci. 2016, 41, 157-162. [CrossRef]

48. Tachikawa, T.; Kaku, M.; Iwasaki, A.; Gesch, D.B.; Oimoen, M.J.; Zhang, Z.; Danielson, J.J.; Krieger, T.; Curtis, B.; Haase, J. ASTER Global Digital Elevation Model Version 2-Summary of Validation Results; NASA: Washington, DC, USA, 2011.

49. Su, Z.; Liu, J.; Zhang, L.; Wang, E. Quantifying the late stage topographic evolution of orogenic belts by Fast Fourier Transform spectral analysis: Applications in the Dabie and Micang Shan, China and Sierra Nevada, USA. Chin. J. Geol. 2011, 46, 743-762. [CrossRef]

50. Arivazhagan, S.; Ganesan, L. Texture classification using wavelet transform. Pattern Recognit. Lett. 2003, 24, 1513-1521. [CrossRef]

51. Mulcahy, C. Image compression using the Haar wavelet transform. Spelman Sci. Math. J. 1997, 1, $22-31$.

52. Jafarpour, B. Wavelet Reconstruction of Geologic Facies from Nonlinear Dynamic Flow Measurements. IEEE Trans. Geosci. Remote Sens. 2010, 49, 1520-1535. [CrossRef]

53. Shabou, A.; Baselice, F.; Ferraioli, G. Urban Digital Elevation Model Reconstruction Using Very High Resolution Multichannel InSAR Data. IEEE Trans. Geosci. Remote Sens. 2012, 50, 4748-4758. [CrossRef]

54. Horé, A.; Ziou, D. Image Quality Metrics: PSNR vs. SSIM. In Proceedings of the 20th International Conference on Pattern Recognition, Istanbul, Turkey, 23-26 August 2010; pp. 2366-2369. [CrossRef]

55. Wang, Z.; Bovik, A.C. A universal image quality index. IEEE Signal Process. Lett. 2002, 9, 81-84. [CrossRef]

56. Zhou, W.; Bovik, A.C.; Sheikh, H.R.; Simoncelli, E.P. Image Quality Assessment: From Error Visibility to Structural Similarity. IEEE Trans. Image Process. 2004, 13, 600-612. [CrossRef]

57. Zhu, J.; Pierskalla, W.P. Applying a weighted random forests method to extract karst sinkholes from LiDAR data. J. Hydrol. 2016, 533, 343-352. [CrossRef]

58. Phinzi, K.; Abriha, D.; Bertalan, L.; Holb, I.; Szabó, S. Machine Learning for Gully Feature Extraction Based on a Pan-Sharpened Multispectral Image: Multiclass vs. Binary Approach. ISPRS Int. J. Geo Inf. 2020, 9, 252. [CrossRef]

59. Rodriguez-Galiano, V.F.; Ghimire, B.; Rogan, J.; Chica-Olmo, M.; Rigol-Sanchez, J.P. An assessment of the effectiveness of a random forest classifier for land-cover classification. ISPRS J. Photogramm. Remote Sens. 2012, 67, 93-104. [CrossRef] 
60. Breiman, L. Random forests. Mach. Learn. 2001, 45, 5-32. [CrossRef]

61. Heung, B.; Bulmer, C.E.; Schmidt, M.G. Predictive soil parent material mapping at a regional-scale: A Random Forest approach. Geoderma 2014, 214-215, 141-154. [CrossRef]

62. Fu, B.; Wang, Y.; Campbell, A.; Li, Y.; Zhang, B.; Yin, S.; Xing, Z.; Jin, X. Comparison of object-based and pixel-based Random Forest algorithm for wetland vegetation mapping using high spatial resolution GF-1 and SAR data. Ecol. Indic. 2017, 73, 105-117. [CrossRef]

63. Corcoran, J.M.; Knight, J.F.; Gallant, A.L. Influence of Multi-Source and Multi-Temporal Remotely Sensed and Ancillary Data on the Accuracy of Random Forest Classification of Wetlands in Northern Minnesota. Remote Sens. 2013, 5, 3212-3238. [CrossRef]

64. Naghibi, S.A.; Hashemi, H.; Berndtsson, R.; Lee, S. Application of extreme gradient boosting and parallel random forest algorithms for assessing groundwater spring potential using DEM-derived factors. J. Hydrol. 2020, 589, 125197. [CrossRef] 